\title{
Análise de uma Fundamentação da Verdade de Sentenças Aritméticas
}

[Analysis of Grounds for the Truth of Arithmetical Sentences]

\author{
Edgar L. B. de Almeida*
}

Resumo: O tema deste trabalho é a verdade de proposições matemáticas e seu objetivo é avaliar, no contexto aritmético, um dos elementos presentes em Freire (2018) e também considerado por Ramos e Freire nesta edição da Revista de Filosofia Moderna e Contemporânea: a fixação do valor de verdade de asserções aritméticas a partir de princípios diretivos que regem a prática da disciplina. O método de análise visa à elucidação da contribuição dos princípios diretivos para a fixação do modelo padrão da aritmética e considera três métricas distintas. A partir desses resultados a proposta fundada nos princípios diretivos é comparada com três abordagens alternativas, presentes na literatura especializada. O resultado dessa comparação é bastante favorável à abordagem formulada por Freire e Ramos nesta Revista.

Palavras-chave: aritmética, modelo padrão, condições de verdade.

Abstract: The main subject of this work is the truth of mathematical assertions and its aim is to evaluate, in the arithmetical context, one of the elements featured by Freire in (2018) and in this issue of the Revista de Filosofia Moderna e Contemporânea (in joint work with Ramos): a strategie to fix the truth-condition of arithmetical propositions based on the directive principles that govern the practice of this matter. The method of analysis aims to elucidate the contribution of the directive principles to fix the standard model of arithmetics and takes in consideration three differents metrics. From this results the approach based in principles is compared with other three proposals well known in the literature. The result of this comparison is far favorable to Freire and Ramos' approach in this issue.

Keywords: arithmetic, standard model, truth-condictions.

\section{1 - Introdução}

O escopo deste trabalho - análise de uma proposta de fixação do valor de verdade das sentenças aritméticas - é caro à filosofia da matemática e será investigado com o suporte de sistemas axiomáticos. Contemporaneamente esses sistemas desempenham papel de relevo em discussões de cunho filosófico-matemático pois atuam como ferramentas de des-

\footnotetext{
${ }^{*}$ Professor do Instituto Federal de Educação, Ciência e Tecnologia de São Paulo e Pesquisador Colaborador do Departamento de Filosofia da Universidade de Brasília. E-mail: edgar.almeida@ifsp.edu.br
} 
crição e interpretação da matemática.

Sistemas axiomáticos possuem dois componentes: sistemas formais e modelos. Modelos são de natureza semântica-veritativa, enquanto sistemas formais são de natureza sintático-dedutiva. Grosso modo, os modelos codificam as condições de verdade das proposições do ramo da matemática descrito pelo sistema axiomático e os sistemas formais codificam a linguagem, os métodos de dedução e os termos primitivos da área sob investigação axiomática.

Neste contexto, fixado um sistema formal, há duas possibilidades para os modelos: ou há um único modelo - a menos de isomorfismos - ou há uma infinidade de modelos não isomorfos. Quando ocorre o primeiro caso, diz-se que o sistema formal é interpretado e, no outro caso, que trata-se de um sistema formal não interpretado. Essa nomenclatura é estendida, de modo natural, também aos sistemas axiomáticos: um sistema axiomático é interpretado quando seu sistema formal é interpretado. Grupos são um exemplo canônico de sistema axiomático não interpretado; afinal, toda estrutura que atesta a veracidade dos axiomas de grupo é um modelo genuíno do sistema formal de grupos. O mesmo não ocorre com a aritmética; a posição comparti- lhada por muitos matemáticos e filósofos é que os sistemas axiomáticos da aritmética são interpretados: há, a menos de isomorfismos, um único modelo para a aritmética. Este modelo é o modelo padrão da aritmética.

O entendimento de que há um modelo padrão para a aritmética acarreta consequências imediatas para a análise da verdade nessa disciplina: se há um modelo privilegiado, então as condições de verdade das proposições aritméticas estão codificadas nesse modelo. E, uma vez que as condições de verdade das proposições são preservadas nas sentenças que expressam a proposição, o valor de verdade da proposição pode ser aferido pela inspeção recursiva da sentença. Deste modo, se a estipulação do modelo padrão da aritmética estiver alicerçada em bases robustas, então o mesmo poderá ser dito sobre a verdade das proposições aritméticas. Entretanto, é reconhecidamente problemático fornecer bases segundo as quais um modelo da aritmética possa, justificadamente, ser considerado $o$ modelo padrão.

Ramos e Freire apresentam neste volume da Revista de Filosofia Moderna e Contemporânea uma posição que, dentre outras consequências, funda a verdade de disciplinas matemáticas interpretadas, isto é, disciplinas codifi- 
cadas por sistemas axiomáticos interpretados, em um esquema em "dupla camada". Essa posição também pode ser vista, com maiores detalhes e em outro contexto, em Freire (2018).

Uma das camadas é composta pelo sistema formal e, a outra, pelos princípios diretivos que regem a disciplina. Nesse esquema os modelos não estão alienados das camadas, mas também não são determinados por uma única camada particular. Este trabalho analisa em qual medida os princípios diretivos propostos para a aritmética viabilizam a fixação do modelo padrão da aritmética e, consequentemente, o valor de verdade das sentenças aritméticas. Para isso é conduzida uma análise rigorosa tanto dos princípios diretivos quanto dos métodos de análise dos princípios. É importante destacar que, embora os princípios diretivos não constituam um sistema formal e não sejam substitutos de sistemas formais, são passíveis de investigações lógicas e formais. De fato, é desenvolvida uma análise lógica da contribuição dos princípios diretivos para a fixação do valor de verdade das sentenças aritméticas. A noção de lógica aqui empregada é aquela introduzida por Lindström (1969) e aqui denominada sistema semântico.

Uma vez avaliados os princí- pios diretivos em um sistema semântico, procede-se a avaliação dos sistemas semânticos segundo três métricas, as quais visam quantificar e qualificar aspectos matemáticos, dedutivos e modeloteóricos envolvidos na análise. O resultado dessas investigações estabelece, de modo claro e preciso, em qual medida a adoção dos princípios diretivos contribui para a fundamentação do modelo pretendido da aritmética. Adicionalmente, a análise fornece um subproduto bastante interessante: uma fundamentação original para verdade dos axiomas da aritmética de Peano. Outra consequência da análise é a sugestão que linguagens infinitárias podem desempenhar papel relevante no estudo de questões fundacionais. Por fim, os resultados aqui obtidos acerca da fixação do modelo padrão da aritmética são comparados com três propostas presentes na literatura especializada - o resultado da comparação é bastante favorável às propostas tecidas nesta Revista.

\section{2 - Análise dos princípios direti- vos da aritmética}

Um sistema semântico $\mathbb{L}$ é um par $\left(\mathrm{L}^{\Sigma}, \models\right)$ em que a primeira componente é um conjunto de sentenças em uma assinatura $\Sigma$ e a segunda componente é a relação de satisfatibilidade entre a classe das 
estruturas adaptadas para a assinatura e as sentenças dessa assinatura. Sistemas semânticos não necessariamente são munidos de uma contraparte formal, isto é, não necessariamente há um sistema formal correlato para a relação de satisfatibilidade. Entretanto, este não é o caso para os sistemas semânticos aqui empregados. O sistema formal correlato a um sistema semântico é composto por linguagem formal, conjunto recursivo de axiomas e coleção finita de regras de inferência. Exemplos de tais sistemas semânticos são as formulações canônicas da lógica de primeira ordem, da lógica de segunda ordem e da lógica infinitária que admite sentenças formadas por disjunções enumeráveis e ocorrência de quantificadores apenas em número finito. Tais sistemas serão denotados, respectivamente, $\mathbb{L}_{\omega \omega}, \mathbb{L}_{2}$ e $\mathbb{L}_{\omega_{1} \omega}$. Apresentações sistemáticas desses sistemas podem ser vistas em Ebbinghaus (1985) e Ebbinghaus, Thomas, Flum (1996).

Formalização é o processo de reescrita de sentenças da linguagem natural em uma linguagem formal. Uma das principais características da formalização é a eliminação de ambiguidades e vaguidades que, eventualmente, estejam presentes em sentenças da linguagem natural. Outros aspectos são elencados por Kreisel
(1967), para quem a formalização desempenha papel destacado em processos cognitivos, filosóficos e relativos à prática matemática - isto porque a formalização de um conceito: (i) é parte importante do processo psicológico de entendimento; (ii) é componente essencial de programas fundacionais, tais como o de Hilbert e (iii) desempenha papel de relevo no trabalho diário do lógicomatemático. Exemplos dessa última afirmação são a análise da estrutura cumulativa de conjuntos desenvolvida por Zermelo, a explicação do porquê um problema matemático é um problema aberto com relação a uma teoria e o entendimento do processo de memorização de provas matemáticas. Estas são algumas das razões pelas quais a legitimidade e correção da formalização da linguagem natural não é posta sob suspeita neste trabalho.

Um primeiro passo em direção à análise rigorosa dos princípios diretivos é a formalização dos mesmos. E, ainda que a formalização seja considerada apenas da perspectiva da eliminação de ambiguidades e vaguidades, isso não acarretaria que os princípios diretivos devam ser considerados vagos ou ambíguos. Assumimos, como Freire (2018), que os princípios diretivos da aritmética governam a prática aritmética - não 
há vaguidade ou imprecisão nesta afirmação. A formalização não tem por foco a eliminação de ambiguidades; é um primeiro movimento em direção à avaliação rigorosa do papel dos princípios na fixação do modelo padrão da aritmética.

Uma objeção que pode ser levantada quanto à formalização dos princípios diz respeito a uma pretensa circularidade: a aritmética é governada por princípios diretivos que são formalizados em sistemas semânticos forjados em metateorias impregnadas de noções aritméticas, e tais sistemas são empregados na análise dos princípios diretivos. Mas não há circularidade alguma. Isto porque os princípios diretivos da aritmética precedem conceitualmente os sistemas formais empregados na análise. Esta observação continua válida mesmo quando os sistemas nos quais os princípios diretivos são analisados internalizam completamente a aritmética ou quando a metateoria desses sistemas é a própria aritmética.

$\mathrm{Na}$ formalização dos princípios será empregada a assinatura $\Sigma=\{+, \cdot, s, 0\}$, em que 0 é símbolo de constante, $s$ é símbolo de função unária e tanto + quanto · são símbolos de operações binárias. A interpretação pretendida dos símbolos é a usual: 0 é o numeral que denota o número zero, $s$ é o sím- bolo de função tal que, para cada numeral $t$, temos que st é o numeral que denota o número que é o sucessor do número denotado por $t$. Por sua vez + é o símbolo de operação binária tal que, dados os numerais $t$ e $v$, temos que $t+v$ é o numeral que denota a soma dos números denotados por $t$ e $v$. Analogamente, é o símbolo de operação binária tal que, dados os numerais $t$ e $v$, temos que $t \cdot v$ é o numeral que denota o produto dos números denotados por $t$ e $v$. A não estipulação de uma interpretação pretendida aos símbolos da assinatura inviabiliza a formalização dos princípios. Isso porque a atribuição de símbolos da linguagem formal a termos, relações e expressões da linguagem natural é componente importante da formalização. Não é possível formalizar o discurso normativo aritmético, ou qualquer discurso, se não é atribuída uma interpretação privilegiada aos membros da assinatura da linguagem empregada na formalização da linguagem natural.

A concatenação de sequências de símbolos será representada por - e, com isso, a concatenação das sequências $u$ e $v$ será denotada $u^{-} v$. Os numerais são os termos $s^{m}(t)$, definidos por recursão a partir dos $\sum$-termos $t$ pelas seguintes cláusulas:

$$
s^{0}(t)=t \quad \text { e } \quad s^{m+1}(t)=s^{-} s^{m}(t)
$$


Uma vez que o único termo da assinatura $\Sigma$ em consideração é o símbolo de constante 0 , adotamos a definição recursiva dos numerais em que $s^{0}(0)=0$ e $s^{m}(t)$, para $m>0$, é a expressão formada pela repetição de $m$ símbolos $s$ à esquerda do símbolo 0. Como usual, os numerais $0, s 0, s s 0$, etc, serão representados por $\mathbf{0}, \mathbf{1}, 2$, etc.

O principal objetivo dessa seção é analisar em qual medida os princípios diretivos da aritmética contribuem para a fixação do modelo padrão da aritmética. Visando este fim, diremos que uma coleção de sentenças $\Gamma$ com assinatura $\Sigma$ em um sistema semântico $\mathbb{L}$ fixa a estrutura $\mathcal{A}$ quando $\mathcal{A}$ é modelo de $\Gamma$ e qualquer outro modelo de $\Gamma$ é isomorfo a $\mathcal{A}$. Uma vez que, dada qualquer estrutura $\mathcal{A}$ e qualquer conjunto $X$ equipotente ao domínio de $\mathcal{A}$, há um modo canônico de obter uma estrutura $\mathfrak{B}$, isomorfa a $\mathcal{A}$ e com domínio $X$, não é possível fixar uma estrutura a menos de sua classe de isomorfismos. Posto de outro modo, uma coleção de sentenças fixa uma estrutura quando a coleção de sentenças é, no sentido da teoria de modelos, categórica.

A contribuição dos princípios diretivos para a fixação da estrutura padrão será avaliada do seguinte modo. Primeiro, escolhemos um sistema semântico $\mathbb{L}$ cuja linguagem seja suficiente- mente expressiva para formalizar, ao menos parcialmente, os princípios diretivos a partir da assinatura $\sum$. Uma $\sum$-estrutura $\mathcal{A}$ é correta segundo os princípios diretivos da aritmética quando $\mathcal{A}$ é um modelo do conjunto de sentenças que corresponde a formalização dos princípios diretivos. Neste sentido, os princípios constituem um critério de seleção, dentre todas as $\Sigma$-estruturas, daquelas que são corretas segundo os princípios diretivos. Se quaisquer dois membros na classe das estruturas corretas segundo os princípios diretivos são isomorfos, então os princípios diretivos da aritmética fixam as estruturas aritméticas corretas. Se os princípios diretivos da aritmética fixam as estruturas aritméticas corretas e $\langle\omega,+, \times, s u c, 0\rangle$ é uma estrutura correta, então os princípios diretivos da aritmética fixam o modelo padrão da aritmética.

Fixado o modelo pretendido, é natural que se proceda a uma meta-análise dos princípios diretivos, isto é, que os sistemas semânticos que analisam os princípios diretivos da aritmética sejam submetidos, eles próprios, à análise. Tais sistemas serão avaliados com base em aspectos dedutivos, semânticos e matemáticos. Com relação ao primeiro desses aspectos, uma lógica é avaliada enquanto ciência da dedução 
e o caráter dedutivo encontra-se intrinsecamente associado ao aparato formal. Desta perspectiva, o critério de avaliação dos sistemas semânticos é a completude. Sistemas semânticos nos quais as sentenças válidas sejam demonstráveis no sistema formal correlato são mais bem avaliados do que os sistemas semânticos que não apresentam esta característica.

O caráter semântico está relacionado ao papel de instrumento de identificação de estruturas matemáticas e noções correlatas que os sistemas semânticos podem assumir. Esse aspecto será avaliado, prioritariamente, segundo as propriedades semânticas de Löwenheim-Skolem e compacidade. Secundariamente, serão consideradas a propriedade de interpolação de Craig e definibilidade de Beth. Uma característica de sistemas semânticos munidos da propriedade de LöwenheimSkolem é a impossibilidade de fixar estruturas que possuam domínio infinito. Já os sistemas munidos da propriedade de compacidade não distinguem estruturas com domínio finito, mas arbitrariamente grande, de estruturas com domínio infinito. Sistemas semânticos munidos dessas proprieda- des serão mais bem avaliados do que aqueles que não as possuem. ${ }^{1}$

Sistemas semânticos são impregnados de noções matemáticas e o ambiente natural de avaliação dessas noções é a teoria de conjuntos ZFC. Uma forma usual de avaliar quão impregnado de noções matemáticas encontra-se um determinado conceito, expressável em ZFC, é pela aferição da classe de modelos de ZFC para a qual o conceito sob avaliação é absoluto - quanto maior a classe de modelos, menos impregnada de noções matemáticas encontra-se o conceito em análise. Nos casos considerados neste trabalho, a coleção de sentenças é definida por recursão a partir de uma relação bem fundada e absoluta para modelos transitivos de ZFC. Nestes casos, a coleção de sentenças é absoluta para modelos transitivos de ZFC, como assevera o teorema IV.5.6 em Kunen (1992). Resta, portanto, avaliar para quais classes de modelos a relação de satisfatibilidade é absoluta.

Para comodidade do leitor, uniformidade de notação e sistematização dos resultados, os princípios diretivos para a aritmética presentes no trabalho de Ramos e Freire nesta mesma edição da Re-

\footnotetext{
${ }^{1}$ A razão dessa postura é o endosso ao ponto de vista que distinções entre cardinalidades finitas e infinitas, bem como distinções entre duas cardinalidades infinitas exigem que sejam adotados compromissos ontológicos fortes, o que afasta os sistemas capazes de tais distinções do escopo da lógica em sentido estrito.
} 
vista de Filosofia Moderna e Contemporânea são listados a seguir.

$1^{\circ}$ Princípio Diretivo $\left(\mathrm{PD}_{1}\right)$ : cada número é denotado por um único numeral, que é um objeto sintático obtido pela repetição, possivelmente vazia, de um simbolo primitivo.

$2^{\circ}$ Princípio Diretivo $\left(\mathrm{PD}_{2}\right)$ : cada numeral denota um único número.

$3^{\circ}$ Princípio Diretivo $\left(\mathrm{PD}_{3}\right)$ : dados dois numerais $s$ e $t$, a soma dos números denotados por s e t é denotada pelo numeral obtido pela repetição do símbolo primitivo determinado por s sobre $t$.

$4^{\circ}$ Princípio Diretivo $\left(\mathrm{PD}_{4}\right)$ : dados dois numerais se t, o produto dos números denotados por se té denotado pelo numeral obtido pela repetição da repetição $s$ determinada por $t$.

\section{1 - Análise dos princípios dire- tivos em primeira ordem}

Linguagens de primeira ordem são bastante expressivas, o que é atestado pelo fato de parte significativa da matemática contemporânea ser descrita em uma dessas linguagens - a linguagem da teoria de conjuntos ZFC. Mas não é possível formalizar, em primeira ordem e com uma única sentença, a expressão "a todo número corresponde um único numeral". ${ }^{2}$ Uma vez que o princípio diretivo $\mathrm{PD}_{1}$, apresentado através de uma expressão em linguagem natural, não pode ser formalizado por uma única sentença em linguagem de primeira ordem, dizemos que este princípio não admite uma formalização plena em primeira ordem. Entretanto, podese apelar ao esquema de indução presente nas axiomatizações em primeira ordem da aritmética de Peano e estabelecer uma correlação entre o princípio diretivo $\mathrm{PD}_{1}$ e as infinitas instâncias do esquema de indução. Essa correlação pode ser entendida como uma formalização parcial do princípio diretivo $\mathrm{PD}_{1}$.

Uma maneira de enunciar o princípio da indução é: considere uma propriedade que se aplica aos números; se o número zero goza

\footnotetext{
${ }^{2}$ Uma dificuldade em formalizar essa expressão deve-se ao fato que, na abordagem sob análise, números são vistos como os elementos do domínio de estruturas corretas segundo os princípios diretivos. Uma formalização da expressão em discussão deve condensar a informação de que todos os elementos no domínio de uma estrutura correta segundo os princípios desempenham papel de número. Com isso, dada uma estrutura correta $\mathcal{A}$, para todo $x$, se $x$ é elemento do domínio de $\mathcal{A}$, então $x=0^{\mathcal{A}}$ ou $x=(s 0)^{\mathcal{A}}$ ou $x=(s s 0)^{\mathcal{A}}$ ou $\cdots$ Uma tal disjunção infinta não pode ser formalizada em primeira ordem, embora seja facilmente formalizada na linguagem do sistema semântico infinitário que consideramos no corpo deste trabalho. Ademais, se houvesse uma sentença de primeira ordem $\varphi$ que formalizasse a expressão em análise, então uma estrutura $\mathcal{A}$ seria modelo de $\varphi$ se, e somente se, o domínio de $\mathcal{A}$ fosse infinito e enumerável, o que claramente não pode ser o caso.
} 
desta propriedade e, se sempre que um número possui tal propriedade seu sucessor também a possui, então todos os números naturais possuem a propriedade em consideração.

Por um lado, o princípio diretivo $\mathrm{PD}_{1}$ pode ser empregado para justificar o princípio da indução. Suponha $\mathrm{PD}_{1}$ e que há uma propriedade acerca dos números naturais tal que (i) o número zero goza dessa propriedade, (ii) se um número possui tal propriedade, então seu sucessor também a possui e (iii) há um número que não possui a propriedade. Pela condição (i) o número denotado por 0 goza dessa propriedade e, pela condição (ii), se o número denotado por $\mathbf{k}$ possui a propriedade, então o número denotado por $s \mathbf{k}$ também possui tal propriedade. Decorre da definição recursiva que os numerais são esgotados pelas condições (i) e (ii) e, consequentemente, o número em (iii) que não goza da propriedade não pode ser denotado por um numeral, o que contraria $\mathrm{PD}_{1}$.

Por outro lado, o princípio da indução pode ser usado para explicar o princípio diretivo. Admita o princípio da indução e que a propriedade considerada é "ser denotado por um numeral". A propriedade é desfrutada pelo número zero, pois este pode ser denotado pelo numeral $\mathbf{0}$. O passo indutivo também é o caso, pois se um número é denotado pelo numeral $\mathbf{k}$, seu sucessor pode ser denotado por $s \mathbf{k}$. Logo, é o caso que todo número é denotado por um numeral.

A partir da interpretação fornecida aos termos primitivos da linguagem aritmética os demais princípios diretivos podem ser formalizados, plena e facilmente, em primeira ordem. O princípio diretivo $\mathrm{PD}_{2}$ estabelece que numerais distintos denotam números distintos. Os números são elementos do domínio das estruturas corretas segundo os princípios e os numerais são termos gerados recursivamente. Disto, uma formalização do segundo princípio diretivo é a expressão

$$
\forall m \forall n\left(m \neq n \rightarrow s^{m}(0) \neq s^{n}(0)\right) .
$$

$\mathrm{O}$ princípio $\mathrm{PD}_{3}$ estabelece que a soma de dois números é denotada pela soma dos numerais que denotam cada um dos números. Os numerais são definidos pela concatenação do símbolo $s$ e, desse modo, é natural estabelecer que a soma de numerais é dada pela justaposição, à esquerda, da sequência de símbolos $s$ ao outro numeral. Por exemplo, a soma do numeral $s 0$ com o numeral ss 0 é a concatenação $s^{-} s s(0)$, isto é, $s s s 0$. A partir dessas considerações é razoável formalizar $\mathrm{PD}_{3}$ por

$$
\forall m \forall n\left(s^{m+n}(0)=s^{m}(0)+s^{n}(0)\right) .
$$


A formalização de $\mathrm{PD}_{4}$ é análoga ao do $\mathrm{PD}_{3}$ e escrita como

$$
\forall m \forall n\left(s^{m \cdot n}(0)=s^{m}(0) \cdot s^{n}(0)\right) .
$$

Admitindo-se que os princípios diretivos regem a prática aritmética, a formalização aponta para uma justificativa plausível e fundamentada dos axiomas de Peano. De fato, se a formalização dos princípios diretivos da aritmética em primeira ordem é uma axiomatização da arimética de Peano, os axiomas são asserções aritméticas verdadeiras não porque eles são verdades evidentes acerca dos números; afinal, não parece não problemático afirmar que todas as infinitas instâncias do princípio da indução são verdades evidentes. Tampouco parece razoável que os axiomas sejam vistos como verdadeiros pelo fato de constituírem uma adaptação, no que tange a expressividade, da veracidade dos axiomas da aritmética estipulados por Peano na linguagem de segunda ordem. Uma vez que se aceite a tese de que há princípios que regulamentam a aritmética e estes são explicitados por $\mathrm{PD}_{1^{-}}$ $\mathrm{PD}_{4}$, os axiomas da aritmética de Peano em primeira ordem não devem ser postos sob suspeição porque são formalizações, não plenas, dos princípios diretivos que regem a aritmética. E uma vez que seja aceita a proposta de que os princípios diretivos regem a prá- tica aritmética, conclui-se que a adequação dos axiomas de Peano também é fundada na prática.

Conversamente, se os axiomas da aritmética de Peano são considerados não problemáticos, então não se pode advogar contra a adequação dos princípios $\mathrm{PD}_{1^{-}}$ $\mathrm{PD}_{4}$ pois estes são traduções, para a linguagem natural, daqueles.

Fixada uma linguagem e formalizados os princípios diretivos, procede-se a investigação do papel destes com relação a fixação da estrutura padrão. A classe de estruturas corretas segundo os princípios diretivos pode, certamente, ser considerada uma noção matemática. E o ambiente para a análise de noções matemáticas é, por excelência, a lógica de primeira ordem. As razões para esse reconhecimento são consonantes com as métricas que propomos para a avaliação dos sistemas semânticos. Do ponto de vista dedutivo, sistemas semânticos de primeira ordem são completos; quanto ao critério matemático, assim como o conjuntos das sentenças, a relação de satisfatibilidade é absoluta para todos os modelos transitivos de ZFC, resultado folclórico presente, por exemplo, na seção 5 do capítulo 3 de Drake (1974). Do ponto de vista semântico, valem as propriedades de LöwenheimSkolem, compacidade, definibilidade de Beth e interpolação de 
Craig.

Quando as teses que os princípios diretivos regem a prática aritmética e que a prática deve fundamentar a fixação do modelo pretendido são endossadas, o fato da análise dos princípios em sistemas semânticos de primeira ordem não fixar o modelo pretendido pode ser creditado à limitação expressiva da linguagem de primeira ordem - e, se este for o caso, linguagens mais expressivas devem contribuir para a fixação do modelo pretendido. Mas, embora a formalização dos princípios diretivos em primeira ordem não fixe o modelo pretendido da aritmética, a abordagem normativa motiva uma diferenciação importante na classe de modelos dos sistemas formais aritméticos. Essa diferenciação se faz necessária pois nenhum sistema formal, em primeira ordem, é capaz de diferenciar o modelo pretendido dos demais modelos do sistema formal. Naturalmente, o elemento fundante da identificação do modelo padrão de um sistema formal não podem ser as pretensões de quem formata o sistema. Uma saída é oferecida pelos princípios diretivos, segundo o entendimento de que um modelo não padrão é um modelo do sistema formal que não se conforma a algum dos princípios diretivos.

Por exemplo, consideremos a teoria cuja linguagem é a linguagem da aritmética de Peano acrescida de um símbolo de constante $c$ e cujos axiomas são os da aritmética de Peano, estendidos com uma coleção recursiva de axiomas da forma $c \neq \mathbf{0}, c \neq 1, c \neq 2, \ldots$ Esta teoria é consistente e tem modelo $\mathbb{C}$, cujo reduto apropriado é modelo da aritmética de Peano. Mas a estrutura $\mathbb{C}$ não é um modelo pretendido da aritmética, pois não é correta com relação ao princípio diretivo $\mathrm{PD}_{1}$.

Sabidamente, elemento importante para a não fixação da estrutura padrão pela formalização dos princípios diretivos, em primeira ordem, é o teorema ascendente de Löwenheim-Skolem. Na sequência, os princípios diretivos serão formalizados em linguagens mais expressivas do que a de primeira ordem e o resultado será avaliado em sistemas semânticos nos quais não vale a versão ascendente de Löwenheim-Skolem.

\subsection{Análise dos princípios direti- vos em segunda ordem.}

Posto que a linguagem de primeira ordem é um fragmento da linguagem de segunda ordem, toda sentença da primeira é uma sentença da segunda e, consequentemente, os princípios diretivos $\mathrm{PD}_{2}-\mathrm{PD}_{4}$ podem ser formalizados pelas mesmas expres- 
sões empregadas nas considerações acima, relativas à primeira ordem. Quanto ao princípio diretivo $\mathrm{PD}_{1}$, em segunda ordem é possível a formalização plena, isto é, expressar $\mathrm{PD}_{1}$ em uma única sentença da linguagem formal. Uma apresentação dos princípios diretivos são as sentenças a seguir, em que $P$ é uma variável de predicado que, possivelmente, emprega parâmetros.

$$
\begin{gathered}
\text { Princípio } \mathrm{PD}_{1}: \\
\forall P[P(0) \wedge \forall x(P(x) \rightarrow P(s x)) \\
\rightarrow \forall x P(x)] .
\end{gathered}
$$

Princípio $\mathrm{PD}_{2}$ :

$\left.\forall m \forall n(m \neq n) \rightarrow s^{m}(0) \neq s^{n}(0)\right)$.

Princípio $\mathrm{PD}_{3}$ :

$\forall m \forall n\left(s^{m+n}(0)=s^{m}(0)+s^{n}(0)\right)$.

Princípio $\mathrm{PD}_{4}$ :

$\forall m \forall n\left(s^{m \cdot n}(0)=s^{m}(0) \cdot s^{n}(0)\right)$.

Claramente, a formalização dos princípios diretivos corresponde aos axiomas da aritmética de Peano em segunda ordem. Portanto, de modo análogo ao discutido anteriormente, a adequação dos axiomas da aritmética de Peano em segunda ordem pode ser asseverada pois corresponde à formalização dos princípios diretivos. Segundo essa perspectiva, não são os axiomas de $\mathrm{Pe}$ ano que motivam ou estabelecem os princípios diretivos da aritmética; os princípios legislam sobre a aritmética e devem ser vistos como anteriores ao sistema formal. Disto, o fato dos axiomas corresponderem à formalização dos princípios deve ser considerada como uma evidência favorável à correção dos axiomas, não o inverso.

Uma resposta afirmativa para a questão da fixação da estrutura padrão da aritmética a partir dos princípios diretivos é fornecida pelo teorema de categoricidade de Dedekind: toda $\Sigma$-estrutura que é modelo da formalização dos princípios diretivos da aritmética em segunda ordem é isomorfa à estrutura padrão $\langle\omega,+, \times, s u c, 0\rangle$. A demonstração desse resultado pode ser vista em Almeida (2017; teorema 1.2.1).

Uma vez que a linguagem de segunda ordem é bastante corriqueira na prática matemática e a formalização dos princípios nessa linguagem fixa a estrutura padrão da aritmética, poder-se-ia argumentar que a apresentação de bases para a fixação do modelo canônico da aritmética está concluída. Mas há uma crítica forte e imediata a este encaminhamento: linguagens de segunda ordem estão sujeitas a diversas críticas.

A situação é particularmente problemática pois há duas interpretações para o escopo das variáveis de segunda ordem, a interpretação ampla e a interpreta- 
ção de Henkin - conforme Shapiro (1991) - das quais redundam sistemas semânticos de segunda ordem distintos. A possibilidade de mais uma semântica para a linguagem formal não é estritamente problemática. De fato, há duas interpretações possíveis para as variáveis livres de uma fórmula da linguagem de primeira ordem, a interpretação condicional e a interpretação de generalidade, que podem ser vistas, por exemplo, em Freire (2009) e Kleene (1967). Mas, em primeira ordem, a escolha da semântica não é particularmente problemática, pois ambas são inter-interpretáveis. mesmo não ocorre com as interpretações de segunda ordem ampla e de Henkin.

Se a semântica de Henkin é adotada, a interpretação dos quantificadores é sujeita a críticas quanto à arbitrariedade da interpretação, isto porque o escopo dos quantificadores sofrem restrições arbitrárias. Por exemplo, se $\Sigma=\{P\}$, em que $P$ é uma variável de predicado unário e $\mathcal{A}$ é uma $\sum$-estrutura de domínio $A$, então a relação

$$
\mathcal{A} \models \forall P \varphi(P)
$$

não deve ser entendida como "para todo subconjunto $C \in \mathcal{P}(A)$, é o caso que $\mathcal{A} \models \varphi(P)[C]$ "; deve, sim, ser entendida como "para todo subconjunto $C \in d \subseteq \mathcal{P}(A)$, é o caso que $\mathcal{A} \vDash \varphi(P)[C]$ ". Isto constituí uma restrição completamente arbitrária no escopo do quantificador, pois a restrição $d$ na coleção de subconjuntos de $A$ é arbitrária. Além deste, há outro problema com a semântica de Henkin: o sistema semântico resultante pode ser interpretado no sistema de primeira ordem, algo que influencia e contamina a análise em segunda ordem.

A semântica ampla suporta a categoricidade da aritmética de Peano e possui uma alegada naturalidade semântica, pois não restringe de modo arbitrário o escopo de quantificação. Entretanto, essa interpretação não é livre de críticas. Uma delas é apontada por Putnam (1980) no contexto de estabelecer os referentes dos elementos do vocabulário da linguagem de segunda ordem:

[A] interpretação 'pretendida' do formalismo de segunda ordem não é fixada pelo uso do formalismo (o próprio formalismo admite os chamados modelos de Henkin [‥]), e [assim] torna-se necessário atribuir a mente poderes especiais para 'agar-

\footnotetext{
${ }^{3}$ Tradução nossa do original: (...) the 'intended' interpretation of the second-order formalism is not fixed by the use
} 
rar' noções de segunda ordem. ${ }^{3}$

Uma vez que a lógica de segunda ordem é passível de discussão quanto à interpretação dos quantificadores e, como aponta Putnam, devem ser feitos apelos a propriedades subjetivas para a adoção da semântica e fixação do referente, é razoável considerar que os sistemas semânticos de segunda ordem não são a ferramenta ideal para a análise dos princípios diretivos da aritmética.

Relacionada e adicionalmente a essas críticas, os sistemas semânticos de segunda ordem são muito mal avaliados pelas métricas fixadas. Do ponto de vista dedutivo, não há aparato sintático que seja completo para a semântica ampla. Da perspectiva semântica, o sistema não é dotado das propriedades de Löwenheim-Skolem, compacidade, definibilidade de Beth ou interpolação de Craig.

Por fim, uma fonte recorrente de críticas às linguagens de segunda ordem é a expressividade dessas linguagens. Afinal, segundo Tharp (1975), o elevado poder expressivo permite que questões matemáticas sofisticadas sejam reduzidas à pura semântica.

O poder expressivo desta lógica [de segunda ordem], que é demasiado grande para admitir um procedimento de prova, é adequado para expressar declarações conjuntistas. Questões abertas típicas, como a hipótese do contínuo ou a existência de grandes cardinais, são facilmente declaradas como questões da validade de fórmulas de segunda ordem. Assim, os princípios dessa lógica fazem parte de uma área ativa e um pouco esotérica da matemática. Parece haver um sentimento justificável de que esta teoria deve ser considerada matemática, e que lógica deve ser mais auto-evidente e menos aberta. ${ }^{4}$

Se os princípios diretivos fixam o modelo padrão e se tais princípios são considerados anteriores a algumas noções matemá-

\footnotetext{
of the formalism (the formalism itself admits the so-called 'Henkin models' (...), and it becomes necessary to attribute to the mind special powers of 'grasping second-order notions'. (1980; p. 481).

${ }^{4}$ Tradução nossa do original: "The expressive power of this logic [second-order], which is too great to admit a proof procedure, is adequate to express set-theoretical statements. Typical open questions, such as the continuum hypothesis or the existence of big cardinals, are easily stated as questions of the validity of second order formulas. Thus the principles of this logic are part of an active and somewhat esoteric area of mathematics. There seems to be a justifiable feeling that this theory should be considered mathematics, and that logic - one's theory of inference - is supposed to be more self-evident and less open." (1975; p. 38).
} 
ticas e aos sistemas formais, então é certamente desejável que a ferramenta de análise dos princípios faça o mínimo de referência a tais noções. E, embora seja reconhecidamente problemático caracterizar precisamente a extensão de "mínimo de referência a noções matemáticas", a citação acima revela a percepção que, quando se trata da lógica de segunda ordem, o mínimo é extrapolado. Essa crítica à permeabilidade do sistema semântico por noções matemáticas é consonante com a análise da relação de satisfatibilidade, pois esta é absoluta apenas para modelos supertransitivos de ZFC. ${ }^{5}$

Quando formalizados em segunda ordem, os princípios diretivos fixam a estrutura padrão da aritmética. Mas a análise do sistema semântico que viabiliza a fixação da estrutura padrão fomenta objeções sérias e que podem obscurecer a real contribuição dos princípios diretivos. $\mathrm{O}$ emprego de uma linguagem menos expressiva certamente é valoroso.

\section{3 - Análise dos princípios dire- tivos em linguagem infinitária}

Na linguagem formal ora em consideração as variáveis são, exclusivamente, variáveis individu- ais. E são admitidas fórmulas de comprimento infinito enumerável, mas nas quais o número de ocorrências de variáveis ligadas é finito. Tal linguagem, diferentemente da linguagem de segunda ordem, não está muito presente no discurso matemático, embora ocorram exceções marcantes como, por exemplo, apresentações canônicas dos grupos de torção. A baixa expressividade, quando comparada a segunda ordem, associada a propriedades metateóricas que a aproximam bastante da primeira ordem, podem ser consideradas explicações da pouca aplicação. Uma apresentação dessa linguagem e do correspondente sistema semântico $\mathrm{L}_{\omega_{1} \omega}$ pode ser vista em Keisler (1971).

Assim como na linguagem de segunda ordem, a formalização dos princípios diretivos na linguagem infinitária é plena. O princípio $\mathrm{PD}_{1}$ pode ser formalizado pelo emprego de um quantificador universal e uma disjunção enumerável. E, por se tratar de uma extensão da linguagem de primeira ordem, os demais princípios podem ser formalizados pelas mesmas expressões formais empregadas em primeira ordem. Entretanto, será apresentada outra formalização, com o emprego de sentenças com comprimento enume-

\footnotetext{
${ }^{5}$ Consequência da operação “tomar as partes" na semântica de segunda ordem e de II.4.24 em Kunen (2011).
} 
rável e sem apelo ao emprego de quantificadores.

$$
\begin{aligned}
& \text { Princípio } \mathrm{PD}_{1} \text { : } \\
& \forall x \bigvee_{m \in \omega}\left(x=s^{m}(0)\right) \text {. } \\
& \text { Princípio } \mathrm{PD}_{2} \text { : } \\
& \bigwedge_{m \in \omega} \bigwedge_{n \in \omega \backslash\{m\}}\left(s^{m}(0) \neq s^{n}(0)\right) \text {. } \\
& \text { Princípio } \mathrm{PD}_{3} \text { : } \\
& \bigwedge_{m \in \omega} \bigwedge_{n \in \omega}\left(s^{m}(0)+s^{n}(0)=s^{m+n}(0)\right) \text {. } \\
& \text { Princípio } \mathrm{PD}_{4} \text { : } \\
& \bigwedge_{m \in \omega} \bigwedge_{n \in \omega}\left(s^{m}(0) \cdot s^{n}(0)=s^{m \cdot n}(0)\right) \text {. }
\end{aligned}
$$

A correção da formalização dos princípios nas expressões acima é imediata. O princípio $\mathrm{PD}_{1}$, por exemplo, afirma que todo número é denotado por um numeral. Assim, um número qualquer é denotado por 0 ou $s 0$ ou $s s 0$ ou ..., e essa disjunção enumerável pode ser formalizada pela primeira expressão acima. A formalização dos demais princípios é também é imediata. O teorema de categoricidade para $\mathrm{L}_{\omega_{1} \omega}$, a seguir, responde afirmativamente ao problema da fixação da estrutura padrão com base nos princípios.

Teorema 1 Toda L-estrutura que satisfaz a formalização dos princípios diretivos da aritmética em $\mathbb{L}_{\omega_{1} \omega}$ é isomorfa à estrutura padrão.

Prova. Sejam $\langle\omega,+, \times, s u c, 0\rangle \quad$ o modelo padrão e $\langle A, \oplus, \otimes, m u, c\rangle$ uma $\sum$-estrutura $\mathcal{A}$. Definimos a função $h$ de domínio $\omega$ e codomínio $A$ pelas cláusulas recursivas (i) $h(0)=c$ e (ii) $h(\operatorname{suc}(a))=m u(h(a))$. Grosseiramente, o 'zero' da estrutura canônica é levado, por $h$, no zero da estrutura $\mathcal{A}$ e $h$ mapeia a sucessão de modo homogêneo. Por indução em $\omega$ mostramos facilmente que $h$ é injetiva. A sobrejetividade de $h$ é consequência direta de $\mathcal{A}$ ser modelo da formalização de $\mathrm{PD}_{1}$ - de fato, claro está que a interpretação do $\sum$-símbolo de função $s$ é $m u$ e, consequentemente, pela formalização de $\mathrm{PD}_{1}$, se $a \in A$, então $a=c$ ou $a=m u(b)$, para algum $b \in A$. A verificação que $h$ preserva as propriedades estruturais da soma e produto, isto é, que (i) $h(a+b)=h(a) \oplus h(b) \mathrm{e}$ (ii) $h(a \times b)=h(a) \otimes h(b)$, é feita facilmente a partir das formalizações dos princípios diretivos $\mathrm{PD}_{3}$ e $\mathrm{PD}_{4}$. Consequentemente, $h$ é um isomorfismo de $\langle\omega,+, \times, s u c, 0\rangle$ em $\langle A, \oplus, \otimes, m u, c\rangle$.

Formalizados na linguagem infinitária, os princípios diretivos fixam o modelo pretendido da aritmética. E o sistema semântico empregado é bem avaliado pelas métricas adotadas. De fato, pelo critério semântico a lógica infinitária $\mathrm{L}_{\omega_{1} \omega}$ não padece dos mesmos problemas da lógica de segunda ordem. Não há propostas consolidadas de interpretações concorrentes para os quan- 
tificadores. Além disso, esses sistemas são dotados da propriedade de Löwenheim-Skolem, bem como das propriedades de interpolação de Craig, definibilidade de Beth e um resultado que mimetiza, em muitas aplicações, a compacidade. ${ }^{6}$ Se são admitidas apenas fórmulas de comprimento enumerável e deduções a partir de um conjunto enumerável de sentenças, há uma contraparte sintática para $\mathbb{L}_{\omega_{1} \omega}$ que é adequada do ponto de vista dedutivo, isto é, há um aparato de prova que é correto e completo com relação a semântica, conforme Keisler (1971; cap. 4). Do ponto de vista matemático, $\mathbb{L}_{\omega_{1} \omega}$ se revela muito menos impregnado de noções matemáticas do que os sistemas de segunda ordem. De fato, a relação de satisfatibilidade é absoluta para qualquer modelo transitivo de ZFC que contenha a coleção dos conjuntos hereditariamente contáveis. ${ }^{7}$

O emprego de linguagens infinitárias em análises da aritmética não está isento de críticas. Por exemplo Button e Walsh (2015) destacam que
Nós podemos obter a categoricidade adicionandose à aritmética de $\mathrm{Pe}$ ano em primeira ordem uma disjunção contável dizendo: "tudo é zero, ou o sucessor de zero, ou o sucessor do sucessor de zero, etc.". Mas para capturar essa proposta, nós precisamos capturar o 'etc'.; e isso parece exatamente o desafio original de capturar a (ou uma) sequência de números naturais. $^{8}$

No entanto, essa crítica não se aplica a análise desenvolvida aqui, pois não se trata do problema da 'captura' da sequência numérica por um sistema formal, nem de extensões da aritmética de Peano com sentenças de comprimento enumerável. A posição aqui analisada é que a prática aritmética é regida por princípios que são fundantes da verdade aritmética. O papel desempenhado pelos sistema semântico $\mathbb{L}_{\omega_{1} \omega}$, no que diz respeito à fixação da estrutura padrão, limita-se à formalização e análise dos princípios di-

\footnotetext{
${ }^{6}$ Embora a compacidade não valha em $\mathrm{L}_{\omega_{1} \omega}$, no capitulo 3 de Keisler (1971) há um resultado que desempenha papel análogo ao da compacidade quando se trata de estender resultados modelo-teóricos de $\mathrm{L}_{\omega \omega}$ para $\mathrm{L}_{\omega_{1} \omega}$.

${ }^{7}$ Ver Ebbinghaus $(1986 ; 3.2 .2)$. Mais precisamente, esse resultado diz respeito a satisfatibilidade com relação a conjuntos admissíveis - neste trabalho consideramos o caso particular dos hereditariamente contáveis.

${ }^{8}$ Nossa tradução do original: "(We can) obtain categoricity by adding to first-order Peano arithmetic a countable disjunction saying: "everything is either zero, or the successor of zero, or the successor of that, etc.". But to grasp this proposal, we need to grasp that 'etc.'; and that looks exactly like the original challenge of grasping the (or a) natural number sequence." (2015; p.12).
} 
retivos; não é analisado um conjunto com infinitos números ou a sequência infinita dos números naturais. São, sim, analisados os princípios diretivos que, por hipótese, regem a prática aritmética. $\mathrm{E}$ a análise desses princípios no sistema semântico $\mathbb{L}_{\omega_{1} \omega}$ explicita em qual sentido eles fixam a estrutura canônica. A análise do sistema semântico $\mathbb{L}_{\omega_{1} \omega}$ nos mostra em qual sentido esse sistema é adequado para a análise dos princípios diretivos: este sistema fixa o modelo padrão e é bem comportado segundo métricas semânticas, dedutivas e matemáticas.

Isso nos permite afirmar que, sob essas condições, a estrutura canônica da aritmética é fixada pelos princípios diretivos. E, dentre todas as estruturas adequadas à linguagem da aritmética e que satisfazem os axiomas de um sistema formal aritmético, os princípios diretivos permitem selecionar quais são as estruturas corretas com relação à prática matemática.

Claro que se a semântica da lógica infinitária for formalizada na teoria de conjuntos em primeira ordem, o teorema de categoricidade deixa de valer, mas essa situação é incontornável por se tratar de uma característica do ambiente de análise da semântica infinitária e, não necessariamente, da própria semântica.

Um comentário em favor da adequação do sistema semântico $\mathbb{L}_{\omega_{1} \omega}$ como ambiente de análise de noções matemáticas pode ser tecido a partir das considerações de Bays (2001), relativos a primeira ordem:

[As] noções de finitude e recursão são necessárias para descrever a teoria de modelos de primeira ordem, uma vez que as fórmulas da lógica de primeira ordem podem ser de comprimento finito e arbitrário, mas não infinito, e a relação de satisfação é definida recursivamente. $^{9}$

Para uma teoria de modelo infinitária exige-se que fórmulas de comprimento infinito enumerável sejam aceitas como não problemáticas e que a recursão transfinita enumerável seja aceita como não problemática. Essas exigências são completamente razoáveis, uma vez que em primeira ordem são aceitas fórmulas com comprimento arbitrariamente grande (e vale a compacidade!) e o discurso

\footnotetext{
${ }^{9}$ Tradução nossa do original: "[T] he notions of finitude and recursion are needed to describe first-order model theory, since first-order formulas can be of arbitrary finite length, but they cannot be infinite, and first-order satisfaction is defined recursively." (2001; p. 345).
} 
sobre coleções enumeravelmente infinitas permeia parte significativa da matemática e filosofia da matemática contemporânea.

As considerações tecidas nesta seção acerca do papel dos sistemas semânticos enquanto ferramentas de análise dos princípios diretivos oferecem uma perspectiva de investigação que pode ser de interesse para a filosofia da lógica. Isso porque, pelo teorema ascendente de Lowenheim-Skolem, teoremas de categoricidade para teorias munidas de modelos infinitos devem ser desenvolvidos em extensões da lógica de primeira ordem. Entretanto, o apelo a estas extensões é, em geral, visto como uma petição de princípio, pois estas extensões envolvem o apelo à noções matemáticas que o resultado de categoricidade procurou garantir em primeiro lugar.

$\mathrm{Na}$ análise conduzida neste trabalho não há petição de princípio, pois o que se investiga são as consequências do paradigma segundo o qual os princípios diretivos legislam sobre a aritmética. A adoção deste paradigma fomenta questões acerca de qual linguagem deve ser considerada adequada para a formalização e análise dos princípios. A resposta para essas questões indica que um ambiente bastante adequado é fornecido pelos sistemas semânticos $\mathbb{L}_{\omega_{1} \omega}$. Afinal, estes são os mais bem comportados segundo as métricas adotadas e tanto fixam o modelo pretendido da aritmética quanto permitem a formalização plena desses princípios.

$\mathrm{Na}$ sequência são apresentadas, e comparadas à abordagem via princípios diretivos, estratégias alternativas de fixação do modelo padrão da aritmética.

\section{3 - Análise comparativa}

Nesta seção são esboçadas três propostas de fixação do valor de verdade de sentenças aritméticas. A primeira, McGee (1997), aborda o processo de apreensão da linguagem matemática e consequente fixação do valor de verdade de sentenças. Já a abordagem de Gaifman (2003) fixa o modelo padrão a partir de um critério de minimalidade na classe de modelos do sistema formal. Por fim, o estruturalismo modal de Hellman (1993) fixa a estrutura padrão com apelo a uma linguagem modal bastante expressiva.

A apresentação dessas posições visa a dois objetivos: (i) identificar convergências e divergências entre algumas propostas presentes na literatura e a abordagem normativa ao mesmo problema e (ii) delinear algumas características da interpretação do autor deste trabalho com relação a proposta de Freire (2018) para a 
fixação da verdade aritmética.

\section{1 - Vann McGee, em How We Learn Mathematical Language}

McGee analisa as condições de verdade de sentenças matemáticas dentro do paradigma realista com o objetivo de elucidar algumas das dificuldades enfrentadas por essa tradição na determinação do valor de verdade das sentenças. Uma dessas dificuldades pode ser posta nos seguintes termos:

A concepção realista supõe que o sentido dos termos matemáticos é fixado com suficiente precisão para garantir que uma sentença tenha valor de verdade determinado. Agora, seja qual for o significado de uma expressão linguística, ela o possui em virtude dos pensamentos e práticas dos seres humanos. Nem todo significado é dependente de pensamentos e práticas de seres humanos - o fato de que um céu vermelho pela manhã significa tempestade não é uma ques- tão de convenção - mas o fato de que o numeral '7' se refere ao quarto número primo é uma questão de como escolhemos usar o símbolo. Então, deve haver algo que pensamos, fazemos ou dizemos que fixa o significado pretendido de termos matemáticos. Como somos capazes de fazer isso? ${ }^{10}$

Embora McGee se dedique às sentenças da aritmética e da teoria de conjuntos, serão aqui consideradas apenas as primeiras. Com isso, uma resposta ao problema acima estará bem encaminhada quando houver uma explicação de como nossos pensamentos e práticas fixam o significado dos termos aritméticos de modo preciso e quando for estabelecido para cada sentença aritmética seu valor de verdade.

O problema atacado por McGee não diz respeito à atribuição de referente aos termos aritméticos. Para ele, é ponto pacífico: nossas práticas e pensamentos ao empregar a linguagem aritmética são incapazes de nos permitir discernir entre cópias isomorfas de

\footnotetext{
${ }^{10}$ Tradução nossa do original: "[T]he realistic conception supposes that the meaning of mathematical terms is fixed with sufficient precision to ensure that a sentence has a determinate truth value. Now whatever meaning a linguistic expression has it possesses in virtue of the thoughts and practices of human beings. Not all meaning is thus dependent on human thought and action - the fact that a red sky in the morning means stormy weather isn't a matter of convenction but the fact that the numeral ' 7 ' refers to the fourth prime is a matter of how we have chosen to use a symbol. So there must be something we think, do, or say that fixes the intended meaning of mathematical terms. How are we able to do this?" (1997; p. 35-36).
} 
estruturas aritméticas, o que torna impossível fixar, a menos de isomorfismos, o referente dos termos da linguagem aritmética. Em particular, não há referentes privilegiados para numerais.

Entretanto, a impossibilidade de fixar $o$ referente de um termo aritmético não acarreta a impossibilidade de fixar as condições de verdade de sentenças aritméticas. Mas, então, como sentenças da linguagem aritmética adquirem determinado valor de verdade? Para responder a isso, McGee observa que aprendemos a linguagem da aritmética quando aprendemos a contar objetos concretos tais quais, por exemplo, palitos de sorvete. Mas, uma vez que a prática de contar palitos permite a acomodação de modelos diferentes do pretendido, "algo mais" é necessário; este algo mais, dirá McGeee, é uma teoria matemática. Assim, aprender aritmética é aprender uma linguagem aritmética $e$ aprender uma teoria matemática.

O papel e características dessa teoria matemática são claras:

[O] que precisamos para explicar o fato de que as sentenças aritméticas têm um valor de verdade determinado é uma teoria com as seguintes características: (i) a teoria, juntamente com os fatos matemáticos, deve determinar um valor de verdade exclusivo para cada sentença aritmética, de tal maneira que os axiomas aritméticos aceitos sejam classificados como verdadeiros, e (ii) a teoria deve ser aprendida por seres humanos. ${ }^{11}$

Mas qual seria esta teoria? A resposta óbvia - a coleção de todas as sentenças aritméticas válidas na estrutura padrão da aritmética - é pouco promissora. Isto porque é difícil sustentar que seres humanos aprendam uma teoria que não seja, ao menos, recursiva. Por este motivo, não é razoável supor que a teoria aprendida quando se aprende aritmética é uma teoria de primeira ordem $\mathrm{T}$ que inclui as sentenças aritméticas verdadeiras e segundo a qual uma sentença aritmética $\varphi$ é verdadeira se, e somente, $\varphi$ é consequência lógica de T. Uma saída promissora, aponta McGee, poderia ser a lógica de segunda ordem

\footnotetext{
${ }^{11}$ Tradução nossa do original: "[W] hat we require to account for the fact that purely arithmetical sentences have a determinate truth value is a theory with the following two characteristics: (i) the theory, together with the mathematical facts, must determine a unique truth value for each arithmetical sentence, in such a way that the accepted arithmetical axioms are classified as true, and (ii) the theory must be learnable by human beings." (1997; p. 43).
} 
e, se este fosse o caso, aprender aritmética seria aprender uma teoria: a aritmética de Peano em segunda ordem.

Admitida essa solução, a determinação do valor de verdade das sentenças aritméticas está esclarecido: uma sentença aritmética é verdadeira apenas no caso de ser consequência lógica da teoria e, falsa, apenas no caso de sua negação ser consequência lógica da teoria. Essa solução é aceitável? McGee dirá que, uma vez que a aritmética de Peano em segunda ordem é categórica e formada apenas por axiomas simples, acrescidos do axioma esquema de indução em segunda ordem, se não houver objeções à lógica de segunda ordem, a resposta é sim.

Mas, reconhece McGee, pairam muitas suspeitas sobre a lógica de segunda ordem, o que nos obriga a não nos afastarmos dos recursos da lógica de primeira ordem. Submetendo-se a tais restrições, McGee propõe que aprendemos aritmética através de esquemas e com o auxílio de regras de substituição.

O que aprendemos quando aprendemos um vocabulário matemático não é um conjunto fixo de axiomas de primeira ordem, mas sim um conjunto fixo de axiomas de primeira ordem e esquemas de axiomas. A aritmética de Peano em primeira ordem, como geralmente é apresentada, consiste no axioma esquema de indução, que é a expressão aberta obtida do axioma de indução de segunda ordem, excluindo o quantificador universal inicial, juntamente com uma pequena lista de fatos aritméticos rudimentares. Qualquer expressão (fechada) que pode ser obtida a partir do axioma esquema de indução, substituindo uma expressão aberta pela variável de segunda ordem livre (que, nesse contexto, é chamada de variável esquemática), evitando colisões de variáveis ligadas e, então, prefixando quantificadores universais de primeira ordem, é um axioma de in-

\footnotetext{
${ }^{12}$ Tradução nossa do original: "[W] hat we learn when we learn a mathematical vocabulary is not a fixed set of firstorder axioms, but rather a fixed set of first-order axioms and axiom schemata. First-order Peano Arithmetic, as usually presented, consists of the Induction Axiom Schema, which is the open sentence gotten from the Second-order Induction Axiom by deleting the initial universal quantifier, together with a short list of rudimentary arithmetical facts. Any (closed) sentence that can be gotten from the Induction Axiom Schema by substituting an open sentence for the free secondorder variable (which, in this context, is called a schematic letter), avoiding collisions of bound variables, then prefixing universal first-order quantifiers, is an Induction Axiom.” (1997; p. 57).
} 


\section{dução. ${ }^{12}$}

Quanto ao aprendizado da aritmética,

[O] que nos é ensinado quando aprendemos a linguagem da aritmética são os axiomas de Peano, entendidos de modo que podemos substituir no axioma esquema de indução qualquer sentença aberta que nos agrade. Podemos substituir qualquer expressão aberta do inglês. Além disso, se estendemos o inglês dos dias de hoje com vocabulário adicional, esperamos poder ser capazes de substituir em qualquer expressão aberta do idioma estendido $[\cdots]$. Nossa compreensão da linguagem da aritmética é tal que antecipamos que o axioma esquema de indução, como as leis da lógica, irão persistir em todas essas mudanças. Não há um único conjunto de axiomas de primeira ordem que expresse plenamente o que aprendemos sobre o significado da notação arit- mética quando aprendemos o axioma esquema de indução, já que sempre somos capazes de gerar novos axiomas de indução, pela expansão do idioma. ${ }^{13}$

Com as passagens acima, parece claro que McGee advoga que ao aprendermos aritmética, estamos aprendendo axiomas de primeira ordem e uma "regra" de livre instanciação de um esquema de indução. Esta regra seria poderosa o suficiente para a fixação, a menos de isomorfismos, do referente dos termos aritméticos. Além disso, o aprendizado dessa regra não estaria sujeito às principais objeções da lógica de segunda ordem.

Concordamos integralmente com a posição de McGee acerca da impossibilidade de fixação, a menos de isomorfismo, do referente dos termos aritméticos. Adicionalmente, endossamos sua visão de que a impossibilidade de fixação do referente não impede que sentenças aritméticas tenham valor de verdade determinado e, principalmente, que o valor de verdade das sentenças aritméticas deve ser fixado pela prática,

\footnotetext{
${ }^{13}$ Tradução nossa do original: "Rationally reconstructed, what we are taught when we learn the language of arithmetic is the Peano axioms, so understood that we can substitute into the Induction Axiom Schema any open sentence we like. We can substitute any open sentence of English. Moreover, if we extend present-day English by adjoining additional vocabulary, we expect to be able to substitute in any open sentence of the extended language (...) $(1997 ;$ p. 58).
} 
em harmonia com o modo pelo qual aprendemos aritmética. Entretanto, vemos com ressalvas a solução por ele indicada e acreditamos que proposta de Freire (2018), fundada nos princípios diretivos, fornece uma resposta muito mais natural ao problema da fixação do valor de verdade.

De fato, não nos parece fundado na prática que, ao aprendermos aritmética, estamos aprendendo os axiomas de Peano e que os entendemos de tal maneira que um esquema de indução pode ser instanciado por qualquer sentença que nos agrade, quer seja do léxico atual, quer seja de qualquer extensão do léxico atual. O próprio McGee reconhece a falta de conexão entre sua proposta de aprendizado da linguagem aritmética e os processos educacionais segundo os quais se aprende, desde a tenra idade, aritmética.

Enquanto psicologia do desenvolvimento, a história [que foi contada] tem pouca plausibilidade, uma vez que, de fato, ser treinado para afirmar e concordar com frases matemáticas comple- xas desempenha pouco ou nenhum papel na aquisição, por crianças, do vocabulário matemático. [O que] descrevemos [foi] um processo através do qual o vocabulário matemático é adquirido por uma idealização realista de um aprendiz da linguagem, alguém que executa o mesmo tipo de atividade mental que executamos, mas as realiza sem falhas e incansavelmente. Para que se obtenha sucesso na resolução de nosso problema filosófico, não é requerido que o processo que descrevemos espelhe o processo pelo qual uma criança real aprende o vocabulário; é apenas requerido que o processo não requeira habilidades mentais que sejam de tipos diferentes daquelas realmente observadas em salas de aula. ${ }^{14}$

Em sua defesa, McGee argumenta que suas preocupações não são de natureza pedagógica mas, sim, filosóficas; em especial, ele

\footnotetext{
${ }^{14}$ Tradução nossa do original: "As developmental psychology, the story we are about to tell has little plausibility, since, as a matter of fact, being trained to assert and assent to complex mathematical sentences plays little if any role in children's acquisition of mathematical vocabulary. [...] We describe a process by which mathematical vocabulary is acquired by a realist's idealization of a language learner, one who carries out the same sorts of mental activities we carry out but performs them tirelessly and flawlessly. For the account to succeed in solving our philosophical problem, it is not required that the process we describe resemble the process by which real-life children learn the vocabulary; it is only required that the process not require mental abilities that are different in kind from those observed in actual classrooms." (1997; p. 41-42).
} 
tem interesse em entender como seres com nossas capacidades cognitivas são capazes de entrar em contato com o universo realista. Ademais, se sua proposta resolve um problema filosófico acerca da aquisição da linguagem, não há razões para supor que problemas pedagógicos, relativos ao modo segundo o qual crianças aprendem a linguagem aritmética, serão contemplados pela elucidação filosófica. Por fim, ele argumentará que, se há um descompasso entre a proposta e o processo de aprendizagem, este descompasso é esperado e ocorre sempre que se faz uma reconstrução racional de processos complexos.

Concordamos com McGee que soluções a problemas filosóficos não necessariamente apresentam consequências, ou podem ser estendidos, para a pedagogia ou outras áreas do conhecimento humano. Também endossamos a tese de que reconstruções racionais de processos complexos e dinâmicos apresentam distorções em relação a criação e desenvolvimento dos processos. Mas consideramos que sua hipótese do aprendizado da aritmética envolver o aprendizado de axiomas e um esquema que pode ser livremente instanciado, no léxico presente e futuro, é deveras artificial. Adicionalmente, acreditamos que a adoção de um quadro normativo para a aritmé- tica, governado pelos princípios diretivos elencados, fornece uma solução mais crível para a reconstrução racional da aquisição da linguagem aritmética. Realmente, nos parece muito mais razoável sustentar que crianças, quando expostas a aritmética, entram em contato com um sistema notacional regido pelos princípios em vez do quadro proposto por McGee.

Isto porque parece-nos razoável considerar que, quando aprendermos aritmética, o que quer que aprendamos sobre os números é aprendido através de um sistema notacional. Não somos apresentados a números destituídos de notação; números são representados por numerais e, quanto à manipulação numérica, aprendemos a manipular números ao aprendermos a manipulação da linguagem notacional. Afinal, quando a soma de números é aprendida? Quando é aprendido o algoritmo de transformação de notações correspondente a soma. O mesmo ocorre para a multiplicação: aprender a multiplicar números é aprender o algoritmo da multiplicação dos numerais. Uma vez aprendido o sistema notacional, a comutatividade da soma e da multiplicação são consequências naturais dessas operações, não consequências de instanciações do esquema de indução em alguma extensão da linguagem aritmética. 
Julgamos que, ao supormos que o aprendizado de um sistema notacional regido pelos princípios diretivos da aritmética é o vetor do aprendizado aritmético, nos aproximamos dos processos cognitivos e pedagógicos reais de aprendizado da aritmética. Além disso, pensamos que esta mesma suposição fornece uma solução ao problema de fixação do referente dos termos aritméticos de modo mais plausível que aquela oferecida por McGee. De fato, para fixação do valor de verdade das sentenças aritméticas McGee fixa o referente de termos aritméticos e, para realizar isto a menos de isomorfismos e sem recorrer a lógica de segunda ordem, considera um esquema segundo o qual livres instanciações em expansões ilimitadas da linguagem são permitidas.

A análise desenvolvida na seção anterior revela que a proposta aqui analisada demanda por muito menos recursos. Em vez de aprendermos axiomas e um esquema de indução que admite instanciações misteriosas, aprendemos um sistema notacional muito simples e lógica de primeira ordem, acrescida de disjunção enumerável - não parece crível que disjunções enumeráveis são mais problemáticas do que quaisquer instanciações que nos agrade em quaisquer extensões do léxico atual ou futuro.

\section{2 - Haim Gaifman, em Non- Standard Models in a Broader Perspective}

Gaifman defende que os modelos não padrão da aritmética e da teoria de conjuntos são fontes genuínas de interesse filosófico e matemático. Do ponto de vista matemático, sustenta - e concordamos - que os modelos não padrão são estruturas matemáticas interessantes em si mesmas e objetos legítimos de estudo, além de possuírem diversas aplicações. Estas aplicações ocorrem, por exemplo, quando tais modelos são empregados no estudo de sistemas dedutivos, quando motivam a análise não padrão de Robinson e quando atuam como guias heurísticos para investigações acerca do infinito.

Do prisma filosófico, Gaifman reconhece que Skolem - quem introduziu modelos não padrão nas disciplinas matemáticas - obteve diferentes conclusões conceituais a partir desses modelos: enquanto os modelos não padrão da aritmética são uma evidência da limitação dos sistemas formais de primeira ordem em capturar o modelo pretendido, os modelos não padrão da teoria de conjuntos fornecem suporte a uma posição cética acerca de conjuntos não enu- 
meráveis. A despeito do reconhecimento da posição de Skolem, Gaifman defende que modelos não padrão não podem ser empregados para fomentar ceticismos quanto ao realismo. Esta postura é adotada em oposição ao argumento de Putnam (1980), segundo o qual o realismo é posto em dificuldades quando confrontado com modelos não padrão da teoria de conjuntos. O foco da presente análise não é a crítica de Gaifman ao Putnam mas, sim, algo que a precede: a caracterização de modelo padrão oferecida pelo primeiro.

Após uma breve digressão histórica, em que analisa desenvolvimentos em aritmética, no conceito de função e em geometria, Gaifman identifica três noções para os quais haveria uma interpretação pretendida: a sucessão numérica, a noção de boa ordenação e o conceito de conjunto construtível. Ele, então, procura responder à seguinte questão: Qual, se algum dentre alguns modelos dados, é o modelo padrão? ${ }^{15}$

$\mathrm{O}$ modelo pretendido da sucessão numérica é o modelo padrão da aritmética e Gaifman defende, com inspiração no trabalho de McGee acima discutido e numa condição de minimalidade, a seguinte caracterização:
[O modelo padrão] é o menor modelo, incluído como um segmento inicial em qualquer outro modelo. Se um determinado modelo é não padrão, isso será revelado por um segmento inicial apropriado que é fechado sob a função sucessor. Formalmente, a caracterização é expressa pelo esquema indutivo:

(I) $P(0) \wedge \forall x[N(x) \rightarrow$

$$
\begin{gathered}
(P(x) \rightarrow P(x+1))] \rightarrow \\
\forall x(N(x) \rightarrow P(x)),
\end{gathered}
$$

sendo que ' $N(x)$ ' representa ' $x$ é um número natural' e ' $P(\cdot)$ ' representa qualquer predicado. Qualquer fórmula bem formada da linguagem em uso pode ser um substituto para ' $P(\cdot)$ '. $\quad$ O conceito de sequência de números naturais, contudo, não é dependente da linguagem. ... [para eliminar a dependência] o esquema indutivo deve ser entendido como o metacomprometimento: (II) Qualquer predicado não vago, em qualquer idioma, pode

\footnotetext{
${ }^{15}$ Tradução nossa do original: “Which, if any, of some given models, is the standard one?” (2003; p. 15).
} 
ser substituído por ' $P(\cdot)^{\prime}$ em $(I) .{ }^{16}$

Para Gaifman, o modo como este metacomprometimento deve ser assumido é sintetizada pelo slogan: (Como Vann McGee diz,) se o próprio Deus criar um novo predicado, então esse predicado pode ser substituído por P."17 Não endossamos a proposta de Gaifman e isso não se deve apenas ao seu endosso às ideias de McGee.

A proposta de adoção de um critério de minimalidade para a fixação do modelo padrão não nos parece razoável pois, como o próprio Gaifman aponta, a existência de modelos não padrão é um fenômeno recente na história da matemática - apresentados por Skolem em 1934 para a aritmética e em 1922 para a teoria de conjuntos. Concordamos com Skolem que modelos não padrão da aritmética evidenciam uma limitação dos sistemas formais de primeira ordem e, consequentemente, não nos parece crível sedimentar o modelo padrão enquanto $o$ menor modelo. Isto porque, se os mode- los não padrão são manifestações de sistemas formais de primeira ordem, nos parece que carece de sentido considerar todos os modelos não padrão desses sistemas formais para, então, fixar aquele que é segmento inicial de todos esses modelos e identificá-lo como a interpretação pretendida do discurso aritmético padrão praticado por Diofanto, Gauss, Fermat, etc.

Outra crítica à abordagem de Gaifman é que o tratamento por ele oferecido não é uniforme. Por exemplo, ao analisar o conceito de boa ordenação, a interpretação pretendida é dada pela classe de todos os conjuntos 'verdadeiramente' bem ordenados. Gaifman entende que boa ordenação é uma generalização natural do esquema (I) citado acima, com a condição do predicado $N(x)$ ser substituído por $\operatorname{Ord}(x)$, em que $\operatorname{Ord}(x)$ expressa que " $x$ é ordinal". Disto, e do fato que todo conjunto bem ordenado é isomorfo a um único segmento inicial da classe dos ordinais, ele propõe que essa classe seja a interpretação pretendida da

\footnotetext{
${ }^{16}$ Tradução nossa do original: "[The stantard model] is the smallest model, included as an initial segment in any other model. If a given model is non-standard, then this will be revealed by a proper initial segment that is closed under the successor function. Formally, the characterization is expressed by the inductive scheme: $(I) \quad P(0) \wedge \forall x(N(x) \rightarrow$ $(P(x) \rightarrow P(x+1))) \rightarrow \forall x(N(x) \rightarrow P(x))$ where ' $N(x)$ ' stands for ' $x$ is a natural number', and where ' $P(\cdot)$ ' stands for any predicate. Any wff of the language we are using can be substituted for $P(\cdot)$ The concept of the sequence of natural numbers is, however, not language dependent. The absoluteness of the concept can be secured, if we help ourselves to the full (standard) power set of some given infinite set; for then we can treat ' $P$ ' as a variable ranging over that power set. [...] The inductive scheme should be therefore interpreted as an open ended meta-commitment: (II) Any non-vague predicate, in whatever language, can be substituted for ' $P(\cdot)^{\prime}$ in $(I)$." (2003; p. 15-16)

${ }^{17}$ Tradução nossa do original: "As Vann McGee expresses it, if God himself creates a new predicate, then this predicate can be substituted for 'P'." (2003; p. 15).
} 
noção de boa ordem. Essa solução aponta para a adoção de um critério de maximalidade para a fixação do modelo padrão da noção de boa ordem.

Sem prejuízo a outras críticas que possam ser feitas, propor a fixação do modelo padrão de noções matemáticas a partir de critérios que oscilam entre maximalidade e minimalidade não parece uma boa prática, e pode ser confundido com a não adoção de critérios objetivos.

Quanto à teoria de conjuntos, Gaifman sustenta que se a interpretação padrão da boa ordem por ele formulada é aceita, então qualquer construção indutiva baseada na boa ordem padrão deve ser vista como bem delimitada e não ambígua. Desse modo a classe $\mathbf{L}$ dos construtíveis, que é obtida a partir dessas premissas, é a interpretação pretendida do conceito de conjunto construtível. Gaifman reconhece a debilidade dessa posição e, em sua defesa, apela aos números naturais:

$\mathrm{O}$ argumento baseia-se apenas na plausibilidade de uma construção transfinita, percorrendo todos os ordinais, onde cada es- tágio não é problemático. No entanto, a sugestão é atraente e é reforçada pela observação de que não existem resultados de independência conhecidos para $\mathbf{L}$, do tipo que proliferou na teoria dos conjuntos nos últimos quarenta anos. $\mathbf{L}$ parece a este respeito mais como os números naturais. ${ }^{18}$

Não concordamos com a premissa de Gaifman, pois julgamos que a interpretação padrão da noção de boa ordem é passível de críticas. Adicionalmente, ao comparar os conjuntos construtíveis com os números naturais, Gaifman volta a adotar um critério de minimalidade. Por fim, a suposição de um modelo pretendido para os construtíveis não parece encontrar respaldo na história da disciplina.

Se aceitamos que, além da aritmética, outras disciplinas matemáticas possuem uma interpretação privilegiada, então um método que seja aplicado uniformemente às diversas disciplinas matemáticas é preferível às estratégias que tenham escopo de aplicação particular. Se esta pos-

\footnotetext{
${ }^{18}$ Tradução nossa do original: "The argument rests solely on the plausibility of a transfinite construction, running through all ordinals, where each stage is non-problematic. Yet the suggestion is appealing and it is reinforced by the observation that there are no known independence results for $\mathbf{L}$, of the kind that have proliferated in set theory in the last forty years. L seems in this respect more like the natural numbers." (2003; p. 17).
} 
tura é endossada, então defendemos que, se a fundamentação normativa para a verdade adotada no caso aritmético for estendida para outras disciplinas matemáticas, então o método de fixação do modelo padrão empregado no caso aritmético pode ser estendido a outras disciplinas que tenham modelos pretendidos. Este, de fato, é o caso como a teoria de conjuntos, cujos resultados obtidos em Freire (2018) são harmônicos com a análise aqui desenvolvida para a aritmética.

\section{3 - Geoffrey Hellman, em Mathematics Without Numbers}

Hellman (1993) vê a matemática como a livre exploração de possibilidades estruturais, perseguidas por meios dedutivos (mais ou menos) rigorosos. ${ }^{19}$ Essa posição é alinhada ao estruturalismo, escola em filosofia da matemática para a qual o elemento central das teorias matemáticas são as relações entre os objetos matemáticos, e não a natureza interna desses objetos. O endosso ao estruturalismo conduz ao entendimento de que, em aritmética, o que importa são as relações estruturais entre os itens de uma progressão arbitrária, e não a identidade individual.
Para Hellman, o estudo dos números naturais é um ponto de partida legítimo para análises estruturais. Uma razão para isso é o fato dos números estarem bastante enraigados na prática e pensamento matemáticos. Outra razão é o entendimento de que o estudo dos números é genuinamente estrutural, no sentido que estudar números é estudar as relações dos elementos presentes em $\omega$-sequências arbitrárias.

Tradicionalmente, o ambiente natural de articulação das análises estruturais é a teoria de conjuntos. Entretanto, Hellman defende que este paradigma seja abandonado e uma nova direção seja seguida. Isto porque o paradigma tradicional torna a aritmética dependente da teoria de conjuntos em um nível que, do ponto de vista matemático, seria desejável evitar. Além disto, é salutar evitar que problemas presentes na teoria de conjuntos contaminem a aritmética.

Segundo o estruturalismo professado por Hellman, uma sentença aritmética verdadeira expressa não algo que é o caso em alguma estrutura infinita de um certo tipo mas, sim, o que seria o caso em qualquer estrutura de tipo apropriado que pudesse exis-

\footnotetext{
${ }^{19}$ Tradução nossa do original: Mathematics is the free exploration of structural possibilities, pursued by (more or less) rigorous deductive means. (1993; p. 6).
} 
tir. Isto, contudo, sem que se comprometa com a existência de tal estrutura (ou classe estruturas). Esta postura exime Hellman de se comprometer com a existência de objetos abstratos. Em particular, não há o comprometimento com a existência de estruturas de um certo tipo, embora haja o compromisso com a possibilidade lógica de existência de estruturas de tipo apropriado. Uma vez que há apenas o comprometimento com a possibilidade de existência de estruturas, esta posição é conhecida estruturalismo modal.

Visando à articulação da aritmética dentro dessa visão estruturalista e original, Hellman inicialmente fornece um padrão de tradução (estrutural modal) para a aritmética com o intuito de eliminar toda referência literal aos números. Em seguida, organiza os pressupostos por trás do padrão de tradução para, então, defender a adequação de sua proposta com relação à prática matemática. ${ }^{20}$ Por fim, seguindo o enredo estabelecido para a aritmética, Hellman estende sua visão estruturalista da matemática para a análise real e a teoria de conjuntos.

Concentraremos nossos co- mentários na primeira dessas etapas, o estabelecimento do padrão de tradução estrutural modal das sentenças aritméticas. A razão para isso é simples: julgamos que as exigências que devem ser cumpridas para o estabelecimento da interpretação almejada são um preço muito alto a ser pago pelo não comprometimento ontológico, e seguimos Hellman em (1993; §1, §2) e $(2005 ; \S 1, \S 5)$ para explicar o porquê.

Quando $\varphi$ é uma sentença aritmética, Hellman procura por um padrão de tradução que associe $\varphi$ a um contrafactual da forma:

(A) Se $X$ fosse qualquer $\omega$ sequência, então $\varphi$ seria o caso em $X$.

$O$ padrão de tradução a ser estabelecido e que associa $\varphi$ ao contrafactual (A) deve ser munido das seguintes características: (i) respeitar a objetividade da verdade das sentenças aritméticas e (ii) evitar quantificações sobre estruturas e mundos possíveis - e, consequentemente, evitar o comprometimento com a existência de objetos abstratos. A condição (i) é satisfeita pela adoção de restrições oriundas da matemática, que constituem o componente categó-

\footnotetext{
${ }^{20} \mathrm{~A}$ coordenação dos pressupostos subjacentes à interpretação abarca dois argumentos, um externo ao estruturalismo modal e outro, mais complexo, interno ao estruturalismo. A adequação da proposta para a prática é estabelecida pela descrição da forma como demonstrações aritméticas são recuperadas dentro do estruturalismo modal.
} 
rico do padrão de tradução. Restrições na lógica subjacente fornecem as garantias exigidas por (ii) e constituem o componente hipotético do padrão de tradução.

A linguagem formal na qual o padrão de tradução é forjado emprega um operador primitivo de necessidade modal $\square$. Esta linguagem não está comprometida com a semântica de mundos possíveis e nela a formalização do contrafactual (A) é dada por

$$
\begin{gathered}
\left(\mathrm{A}^{\prime}\right) \square \forall X(X \text { é uma } \omega \text {-sequência } \\
\rightarrow \varphi \text { é o caso em } X),
\end{gathered}
$$

no qual a noção de possibilidade expressa por $\square$ é codificada pelo sistema modal $S_{5}$.

Para que a proposta logre sucesso é preciso formalizar as noções de $\omega$-sequência e satisfatibilidade na linguagem do padrão de tradução. O modo canônico de fazê-lo é via teoria de conjuntos, mas Hellman rejeita essa estratégia pois isso reduziria seu programa estruturalista a um fragmento das teorias de conjuntos modais. A alternativa por ele adotada é considerar que algumas noções de ordem superior serão necessárias, o que remete ao emprego de uma linguagem de segunda ordem.

De posse de uma lógica de segunda ordem modal, Hellman se opõe à formalização usual de " $\varphi$ é verdadeira" como $\square\left(\mathrm{T}_{2} \rightarrow \varphi\right)$, que expressa "é necessário que $\varphi$ seja consequência lógica de $\mathrm{T}_{2}$ ", em que $\mathrm{T}_{2}$ é a conjunção dos axiomas da aritmética de Peano em segunda ordem. Isto porque Hellman não endossa a forma como os símbolos não lógicos da linguagem de $\mathrm{T}_{2}$ são interpretados na lógica modal. O caminho por ele seguido é via a quantificação sobre relações: se $s$ é o único símbolo não lógico da linguagem de $\mathrm{T}_{2}$, então " $\varphi$ é verdadeira" deve ser formalizada por

$$
\square \forall f\left(T_{2} \rightarrow \varphi\right)[s / f],
$$

em que $f$ é uma variável de relação binária e $[s / f]$ indica que $f$ substitui toda ocorrência do símbolo não lógico $s$. A expressão acima é uma sentença que corresponde a asserção metamatemática de que $\varphi$ é consequência lógica dos axiomas de $\mathrm{T}_{2}$.

Hellman destaca que a sentença acima implica questionamentos sobre os domínios das estruturas envolvidas no estabelecimento da consequência lógica. Estes questionamentos são dirimidos pela quantificação sobre tais domínios, resultando em

$$
\square \forall X \forall f\left(T_{2} \rightarrow \varphi\right)^{X}[s / f] .
$$

Se $\psi$ é uma sentença da aritmética de primeira ordem, as operações de soma e multiplicação devem ser definidas de modo usual - por recursão a partir dos 
axiomas de Peano em segunda ordem - e as sentenças que definem essas operações são acrescidas aos axiomas de $\mathrm{T}_{2}$, resultando em $\mathrm{T}_{2}^{\star}$. Com isso, o padrão de tradução (estrutural modal) proposto por Hellman para sentenças $\varphi$ da aritmética de primeira ordem é

$$
\text { (B) } \square \forall X \forall f \forall g \forall h\left(T_{2}^{\star} \rightarrow \varphi\right)^{X} \text {, }
$$

em que $g$ e $h$ são variáveis de relação ternárias e todas as ocorrências de $s,+$ e $\times$ são substituídas por, respectivamente, $f, g$ e $h$.

O esquema (B) acima corresponde ao componente hipotético da interpretação estrutural modal defendida por Hellman e expressa apenas o conteúdo estrutural modal das sentenças aritméticas. Mas, como reconhece Hellman (1993), há muito mais na prática da matemática do que a mera declaração de sentenças. Existe a prática de provar teoremas ${ }^{21}$ e esse "muito mais" deve ser capturado pelo componente categórico.

Este último componente garante a possibilidade de existência de alguma $\omega$-sequência através do axioma

$$
\diamond \exists X \exists f\left(\mathrm{~T}_{2}\right)^{X}[s / f] .
$$

Entretanto, enquanto Hellman se compromete com a possibilidade de existência de uma $\omega$-sequência, ele prefere ser neutro quanto à existência de algo que possivelmente seja uma $\omega$-sequência. Para que este seja o caso a fórmula de Barcan deve ser bloqueada. Isto porque, caso contrário, não há impedimentos à inferência de $\exists X \diamond(X$ é uma $\omega$-sequência) a partir de $\diamond \exists X$ ( $X$ é uma $\omega$-sequência).

Além da fórmula de Barcan, o componente categórico exige um cuidado adicional com o emprego da lógica de base: o axioma da compreensão da lógica de segunda ordem deve ser instanciado, unicamente, por fórmulas $\psi\left(x_{1}, \ldots, x_{n}\right)$ em que não há ocorrência de operadores modais. $\mathrm{O}$ esquema de compreensão, em que $R$ não ocorre em $\psi$, é formulado do seguinte modo:

$$
\diamond \exists R \forall x_{1} \ldots \forall x_{n}\left(R\left(x_{1}, \ldots, x_{n}\right) \leftrightarrow \psi\right) .
$$

Adicionalmente, são incorporados à lógica subjacente ao padrão de tradução alguns elementos mereológicos, que por sua vez conduzem a uma reformulação do esquema de compreensão restrito descrito acima. Mas não precisamos entrar nesses detalhes. O que apresentamos até o momento é suficiente para o ponto ao qual queremos chamar a atenção.

Consideramos extremamente feliz o movimento de Hellman em

\footnotetext{
${ }^{21}$ Tradução nossa do original: "But there is much more to mathematical practice than the mere utterance of sentences. There is the deductive practice of theorem proving.” (1993; p. 10).
} 
direção a posição filosófica que endossa a objetividade do valor de verdade das proposições aritméticas sem, em contrapartida, requerer a existência de objetos abstratos para fixar o valor de verdade das proposições. Entretanto, discordamos dele com relação ao assunto ao qual a aritmética corresponde. Enquanto Hellman vê a aritmética como estudo de relações que ocorrem no interior de possíveis estruturas arbitrárias, para as quais só é oferecida a possibilidade lógica de existência, vemos o assunto aritmética como a atividade performada em obediência aos princípios diretivos. Uma característica marcante da análise desenvolvida por Hellman no contexto aritmético é sua direta adaptação para outros ramos da matemática, em especial a análise real e a teoria de conjuntos. Uma crítica à proposta de Hellman é a falta de clareza quanto em qual medida, se em alguma, a noção de possibilidade presente no trabalho de Hellman é vantajosa, para a aritmética e análise, em comparação àquela presente no estruturalismo que endossa o realismo de estruturas.

Mesmo que Hellman obtenha sucesso e sua proposta se revele superior as outras tradições estruturalistas, se o custo de fixação da verdade de sentenças da aritmética, de modo objetivo e não comprometida com o realismo, é a adoção de uma estratégia escorada em lógica de segunda ordem acrescida tanto do aparato modal $S_{5}$ sem fórmula de Barcan quanto de cuidados especiais no emprego do axioma esquema da compreensão, além de elementos de cunho mereológicos e axiomas de Peano em segunda ordem, então somos bastante reticentes em aceitar a posição defendida por Hellman.

Estamos convencidos que o quadro normativo viabiliza a fixação do valor de verdade das sentenças aritméticas, de modo muito mais natural e sem o comprometimento com objetos abstratos, do que o oferecido por Hellman. Para a lógica de base basta uma linguagem infinitária que, de acordo com as métricas expostas na seção anterior, é bastante próxima da linguagem de primeira ordem. Em vez de elementos categóricos que impõem condições artificiais sobre a lógica de base, são considerados princípios diretivos que são harmônicos com a história da aritmética, são de natureza algorítmica e facilmente aprendidos, além de todas as demais características elencadas nas seções anteriores.

\section{Considerações finais}

Este trabalho consiste em uma análise, para a aritmética, da pro- 
posta presente em Freire (2018) e também abordada por Ramos e Freire neste volume da Revista de Filosofia Moderna e Contemporânea. Tal proposta contempla o problema da fixação do valor de verdade de sentenças de disciplinas matemáticas interpretadas e advoga que as condições de verdade das sentenças aritméticas são determinadas por um esquema em dupla camada. Uma das camadas é composta pelos princípios diretivos e, a outra, por sistemas formais.

Neste artigo os princípios diretivos foram submetidos à rigoroso escrutínio, o que redundou em uma caracterização do modelo padrão para aritmética (através da noção de conformidade aos princípios). A análise também revelou que é factível adotar tais princípios diretivos para a fixação do modelo padrão e que a ferramenta lógica que viabiliza a análise da verdade aritmética a partir dos princípios requer recursos linguísticos, semânticos e matemáticos muito modestos.

Uma vez verificada a viabilidade de fixação da verdade de sentenças aritméticas via princípios diretivos, foram delineadas três propostas bastante populares na filosofia da matemática contemporânea. Isso permitiu ao autor do presente trabalho apresentar, por contraste, algumas de suas impressões acerca da proposta de Freire (2018) e, principalmente, explicitar premissas e comprometimentos assumidos por cada uma das propostas. O resultado dessa comparação é bastante favorável à proposta de cunho normativo e fundada em princípios diretivos.

Há ao menos dois modos naturais de aprofundar a análise da verdade presente neste trabalho. Uma delas diz respeito a compatibilização entre o quadro normativo para a aritmética e uma posição estruturalista modal. Um ponto de partida para análise dessa possível compatibilização pode ser descrito do seguinte modo: se, à la Hellman, a avaliação da verdade de sentenças aritméticas deve ser consequência de um padrão de tradução da sentença com relação a todas as estruturas possíveis, então os princípios diretivos podem ser vistos como um critério que seleciona, dentre todas as estruturas possíveis, aquelas que são as estruturas aritméticas apropriadas as estruturas que se conformam aos princípios. Outra abordagem, certamente interessante e filosoficamente relevante, é a investigação rigorosa dos componentes do pressuposto adotado na investigação das condições de verdade em aritmética. Em particular, uma análise minuciosa e criteriosa da noção de princípio diretivo. Uma 
tal investigação se faz necessária porque, embora a literatura dedicada à discussão e classificação de normas seja extensa, não dispomos de uma caracterização dessa noção que seja harmônica com o quadro geral das investigações aqui apresentadas. O suprimento de tal demanda, no âmbito aritmético, tem potencial para servir de base para a investigação da noção de princípio diretivo para disciplinas matemáticas interpretadas em geral.

Esses tópicos, filosoficamente intrigantes e intelectualmente desafiadores, são temas para trabalhos vindouros.

\section{Referências}

ALMEIDA, Edgar L. B. Análise das Condições de Verdade e dos Requerimentos Existenciais em Axiomatizações da Aritmética. 2017. Tese (Doutorado em Filosofia) Instituto de Filosofia e Ciências Humanas, Univesidade Estadual de Campinas (IFCH/Unicamp). Campinas: 2017.

BAYS, Timoty. On Putnam and his Models. Journal of Philosophy. v. 98, n. 7, p. 331-350. 2001.

BUTTON, T.; WALSH, S. Structure and Categoricity: Determinacy of Reference and Truth-Value in the Philosophy of Mathematics. ArXiv e-prints. 2015. Disponível em <http://adsabs.harvard.edu/ abs/ 2015arXiv150100472B >. Acesso em: 24 dezembro, 2018.

EBBINGHAUS, H. -D. Extended Logics: The General Framework. In: FEFERMAN, S.; BARWISE, J. (Eds.) Model-Theoretic Logics. Springer. New York: Perspectives in Mathematical Logic, p. 25-76. 1985.

EBBINGHAUS, H. -D.; FLUM, J.; THOMAS, W. Mathematical logic. New York: Springer. 1996.

DRAKE, Frank. R. Set Theory, an introduction to large cardinals. Amsterdam: North Holland. 1974.

FREIRE, Rodrigo A. Interpretation and Truth in Set Theory. In: CARNIELLI, W.; MALINOWSKI, J. (Eds.) Contradictions, from Consistency to Inconsistency. Cambridge Univesity Press, p. 183205. 2018.

FREIRE, Rodrigo A. Os fundamentos do pensamento matemático no sáculo XX e a relevância fundacional da teoria de modelos. 2009. Tese 
(Doutorado em Filosofia) Instituto de Filosofia e Ciências Humanas, Univesidade Estadual de Campinas (IFCH/Unicamp). Campinas: 2009.

GAIFMAN, Haim. Non-Standard Models in a Broader Perspective. In: ENAYAT, A.; KOSSAK, R. (Eds.) Non-standard models of arithmetic and set theory. American Mathematical Society, p. 1-22. 2003.

HELLMAN, Geoffrey. Structuralism. In: SHAPIRO, Stewart. (Ed.) The Oxford Handbook of Phylosopy of Mathematics and Logic. Oxford University Press, p. 536-562. 2005.

HELLMAN, Geoffrey. Mathematics Without Numbers: Towards a ModalStructural Interpretation. UK: Oxford University Press. 1993.

KEISLER, Jerome. Model theory for Infinitary Logic: Logic with countable conjunctions and finite quantifiers. Amsterdam: North-Holland. 1971.

KLEENE, Stephen Cole. Mathematical Logic. Dover Publications. 1967.

KREISEL, Georg. Informal Rigour and Completeness Proofs. In: LAKATOS, Imre. (Ed.) Problems in the Philosophy of Mathematics. North-Holland, p. 138-157. 1967.

KUNNEN, K. Set Theory. London: College Publications. 2011.

KUNEN, K. Set Theory: an introduction to independence proofs. Amsterdam: North-Holland. 1992.

LINDSTRÖM, Per. On Extensions of Elementary Logic. Theoria. v. 35, n. 1, p. 1-11. 1969.

MCGEE, Vann. How We Learn Mathematical Language. The Philosophical Review. v 106, n. 1. 1997.

PUTNAM, Hillary. Models and Reality. The Journal of Symbolic Logic. v. 45, p. 464-482. 1980.

RAMOS, Luiza S. P.; FREIRE, Rodrigo A. Da Semântica para Demonstrações de Consistência e a Volta. Revista de Filosofia Moderna e Contemporânea. Brasília, 2018.

SHAPIRO, Stewart. Foundations Without Foundationalism: A Case for Second-Order Logic. Oxford University Press. 1991.

THARP, Leslie H. Which Logic is the Right Logic? Synthese. v. 31, p. 1-21. 1975. 


\section{Agradecimentos}

Agradeço a Rodrigo Freire por apresentar-me ao tema desse artigo e pelas muitas discussões acerca dos assuntos aqui tratados. Agradeço também a Alfredo Roque Freire pela leitura de uma versão prévia do texto e por apontar diversos e valorosos aprimoramentos. Por fim, reconheço que parte significativa do presente trabalho foi realizado com apoio da Coordenação de Aperfeiçoamento de Pessoal de Nível Superior - Brasil (CAPES) - Código de Financiamento 001, durante meu estágio pós-doutoral no Programa de Pós-Graduação em Filosofia da Universidade de Brasília (PPGFIL/UnB). 